\title{
Gait analysis in dogs with pelvic fractures treated conservatively using a pressure-sensing walkway
}

\author{
Flávia Gardilin Vassalo1, Sheila Canevese Rahal ${ }^{1 *}$, Felipe Stefan Agostinho1', Maria Jaqueline Mamprim², \\ Alessandra Melchert ${ }^{3}$, Washington Takashi Kano ${ }^{1}$, Luciane dos Reis Mesquita ${ }^{1}$ and Danuta Pulz Doiche ${ }^{2}$
}

\begin{abstract}
Background: This study aimed to evaluate dogs with pelvic fractures and treated conservatively during locomotion on a pressure-sensing walkway. The hypothesis was that dogs may present changes in kinetic and temporospatial parameters because of the fractures, which may interfere with the symmetry index. Thirty dogs were selected and divided into two groups: Group 1-healthy group $(n=15)$ and Group 2-conservatively treated group $(n=15)$. The dogs were of similar body size. The body weight distribution percentages and symmetry indices of the peak vertical force, vertical impulse, stance time, swing time, percentage of stance time, and percentage of swing time of the hind limbs were evaluated.

Results: In Group 2, the time interval between fracture occurrence and patient evaluation was between 4 and 87 months (mean of 20 months). Four dogs had lower percentage of body weight distribution on one of the hind limbs while three dogs had greater weight distributed toward both hind limbs. Four of these dogs had alterations in the temporospatial and/or kinetic symmetry indices.

Conclusions: Dogs with pelvic fractures treated conservatively may present changes in percentage of body weight distribution and symmetry indices of the kinetic and temporospatial parameters. The conservative treatment can cause persistent abnormal gait.
\end{abstract}

Keywords: Dogs, Gait analysis, Fracture, Treatment, Kinetic

\section{Background}

Pelvic fractures comprise approximately $20-25 \%$ of the fractures observed in small animals with a large percentage being due to motor-vehicle accidents [1-5]. Other causes include fights, falls, kicks, blunt trauma and gunshot wounds, in addition to stress and pathological fractures [2-6].

Around $75 \%$ of the dogs and cats with pelvic fractures are able to recover without a surgical procedure [4]. Included in this category are the pelvic fractures in proper alignment or those comprising less vital portions of the pelvis, and when continuity of the pelvic canal

\footnotetext{
*Correspondence: sheilacr@fmvz.unesp.br

${ }^{1}$ Department of Veterinary Surgery and Anesthesiology, School

of Veterinary Medicine and Animal Science, Botucatu, SP, Brazil

Full list of author information is available at the end of the article
}

remains intact $[1,3]$. This is due to the extensive blood supply to the pelvic bones and heavy muscles surrounding the pelvis that aid in immobilizing the fractured segments $[2,3]$. The perfect anatomical alignment of the fractures is not necessary for their consolidation or function [3]. However, conservative management requires rest of the restricted site for 2-8 weeks [6].

The criteria used to justify surgical intervention are displaced acetabular fractures, especially those involving the cranial $2 / 3$ of acetabulum, severe narrowing of the pelvic canal, neurological changes, ipsilateral fractures of the ilium, ischium and pubis promoting an unstable hip joint, grossly displaced fragments, and other injuries that necessitate early support of the pelvic fractures $[1,3,4$, $6]$. 
To determine the validity for both conservative and surgical treatment, objective methods of gait analysis are necessary $[7,8]$. If the dog presents hind-limb lameness, in general, a load redistribution occurs. The affected limb has lower kinetic parameters that may be increased; for example in the contralateral hind limb and/or ipsilateral forelimb as a compensatory mechanism [9, 10]. Furthermore, the normal locomotion of the dog is considered symmetric, but the presence of neurological or orthopedic injuries may affect this symmetry [8]. A perfect symmetry is represented by an asymmetry index near $0 \%$. Thus, studies have been undertaken to establish appropriate cut-off points for the symmetry indices to identify lameness $[9,10]$.

Although the pressure-sensing walkway has been used in some orthopedic or neurologic conditions in dogs [1114], apparently it has not been used to evaluate dogs with pelvic fracture. The pressure-sensing walkway offer several advantages, such as the possibility of collecting multiple variables and consecutive footfalls that reduces the number of recordings required to produce an adequate amount of data [15-17]. Thus, the present study aimed to evaluate kinetic and temporospatial parameters of dogs with pelvic fractures treated conservatively as presented by their movement on a pressure-sensing walkway. The hypothesis was that dogs may have kinetic and temporospatial changes related to the injury, which may interfere with the symmetry index.

\section{Methods}

\section{Study population}

This study was approved by the Institutional Ethics Committee (no 38/2013-CEUA). Thirty dogs were selected and divided into two groups. Group 1 included 15 clinically healthy dogs (nos. 1-15) and consisted of 12 females and 3 males, mean age of 3.9 years $(\mathrm{SD}=2.1$ years) without prior history of orthopaedic conditions while Group 2 included 15 dogs (nos. 16-30) and consisted of 9 females and 6 males, mean age of 6.0 years $(\mathrm{SD}=3.3$ years $)$ that had pelvic fractures treated conservatively. The dogs in the two groups had similar morphometric measurements.

Age was not considered as inclusion criteria. The majority of the dogs were crossbred $(n=24)$, while the others were Dachshunds $(n=2)$, Yorkshire $(n=1)$, Pinscher $(\mathrm{n}=1)$, Pug $(\mathrm{n}=1)$ and Shih Tzu $(\mathrm{n}=1)$ breeds. Body size was estimated on the basis of forelimb length (distance from dorsal scapular border to the ground), hind limb length (distance from greater trochanter to the ground), and body length (distance from cranial aspect of the scapulohumeral joint to the caudal aspect of the ischial tuberosity). The measurements were performed by using a tape.
The Group 1 dogs were considered to be clinically healthy based on complete physical and orthopedic examinations, and radiographic evaluation of the pelvis and hind limbs. Group 2 included dogs with pelvic fractures that had occurred at least 4 months prior, had not received any anti-inflammatory drugs or pain medications for at least 1 month, and had not received rehabilitation plan or exercise regimen. Exclusion criteria included presence of fractures in other bones, or musculoskeletal changes that could interfere with the analysis. Data regarding cause of injury, time of occurrence, and complications were obtained. Complete physical and orthopedic examinations based on Millis and Levine [18] were performed and included: lameness scores (0: normal; 1 : intermittent lameness; 2 : obvious lameness with weight-bearing; 3: severe lameness with weight-bearing; 4: intermittent lameness without weight-bearing; 5: non-use), presence of pain (slight, moderate, or severe), crepitation of the hip joint during manipulation and hip palpation, and proprioception of the hind limbs. Ventrodorsal hip-extended and lateral radiographic views of the pelvis were obtained to classify the fractures, and to evaluate secondary osteoarthritis related to pelvic fractures.

\section{Data collection}

Immediately before data collection, the dogs were weighed on the same electronic scale. The dogs were submitted to gait analysis using a $1.951 \mathrm{~mm} \times 447 \mathrm{~mm}$ pressure-sensitive walkway (Walkway ${ }^{\circledR}$; Tekscan Inc, South Boston, MA, USA). Designated software (Walkway 7.0 software ${ }^{\circledR}$ ) was used for acquisition and analysis of the temporospatial and kinetic data. Before data collection, each dog was familiarized with the environment and pressure-sensing walkway using practice trials. The dogs were guided on a leash by the same handler across the pressure-sensing walkway in a straight line. The velocity was maintained at $0.9-1.1 \mathrm{~m} / \mathrm{s}$, which was comfortable for the dogs, and the acceleration between -0.15 and $0.15 \mathrm{~m} / \mathrm{s}^{2}$, both recorded by pressure-sensitive walkway system. An average of 25 trials was recorded, and five valid trials were analyzed for each dog. A trial was valid if the limbs had made contact with the surface of the walkway at least two times, without the dog turning the head.

The temporospatial parameters evaluated were gait cycle time (s), stance time (s), swing time (s), and stride length $(\mathrm{m})$. The stance time percentage was established by (stance time/gait cycle time) $\times 100$. The swing time percentage was established by (swing time/gait cycle time) $\times 100$. The stride was determined by the distance between two consecutive ground contacts of the same limb. The kinetic parameters evaluated were peak vertical force (PVF) and vertical impulse (VI). The PVF and VI were normalized to the dog's body weight (BW) and 
characterized by percentage of BW respectively as \%BW and $\% B W \times s$. The percentage of BW distribution among the four limbs during gait was calculated as: (PVF of the limb/total PVF of the 4 limbs) $\times 100$.

\section{Symmetry index}

The symmetry indices between right hind limb (RH) and left hind limb (LH) for Group 1 was calculated for kinetic and temporospatial variables by the following formula: $200[(\mathrm{RH}-\mathrm{LH}) /(\mathrm{RH}+\mathrm{LH})][19]$. The same formula was used for Group 2. Negative values were multiplied by -1 before calculating the mean value of the parameters. A symmetry index (SI) of 0 indicated perfect symmetry. Cut-off values to distinguish between normal hind limbs (Group 1) and abnormal hind limbs (Group 2) were determined by SI of the hind limbs of the Group 1 dogs, as follows: average SI +2 times the SD. Based on this cut-off value, the hind limbs of the Group 2 dogs were considered with or without alteration in the kinetic or temporospatial parameters.

\section{Statistical analysis}

For comparisons of body mass and body size (forelimb length, hind limb length and body length) between the groups, the normality of data was checked by the Kolmogorov-Smirnov test, followed by the unpaired $t$ test. The same tests were used to compare the kinetic and temporospatial parameters between the forelimbs and between hind limbs of Group 1 dogs. Differences were considered significant at $P<0.05$.

\section{Results}

The statistical analysis showed that dogs in Group 1 and Group 2 did not differ in body mass, length of the forelimbs, length of the hind limbs or body length (Table 1).

In Group 2, the mean time interval between fracture occurrence and patient evaluation was between 4 and 87 months (mean 20 months) (Table 2). As to the cause of injury, $93 \%$ of cases were attributed to being hit by a motor vehicle, whereas $7 \%$ were unknown. The most important complication associated with conservative treatment was constipation in one dog (No. 24) due to reduction in pelvic canal width. Signs of slight pain were observed on forced extension of the hip joint in four dogs (Nos. 20, 22, 23 and 28) and restriction of the hip joint in one dog (No. 26). Proprioceptive deficits or signs of fracture movement were not detected. At orthopedic examination, $26.7 \%$ of the dogs had a lameness score of 1 versus $46.7 \%$ presenting a score of 2; signs of lameness were not detected by visual analysis in $26.7 \%$ of the dogs (Table 2).

Radiologic diagnosis of the fractures and indication for surgery or not are described in Table 2 . In $93 \%$ of the cases, the fractures included more than one bone of the pelvis. Of all 15 dogs, 13 had displaced pelvic fractures, and 10 had fractures in three or more directions. The fractures were unilateral in five dogs, and bilateral in ten dogs. Narrowing of the pelvic canal was detected in eight dogs, but only one presented an occurrence of constipation (Table 2). All dogs with articular fracture had signs of osteoarthritis.

Dogs in Group 1 presented no significant differences between right and left forelimbs, and between right and left hind limbs for all variables. The SI values of hind limbs of the Group 1 are described in Table 3. These values were used for comparison of the dogs in Group 2 (Table 4). The dogs 18, 19, 20, 22, 23, 24, 25, 26, 28 and 29 showed kinetic and/or temporospatial changes (Table 4).

\section{Discussion}

In the present study, $93 \%$ of cases presented pelvic fractures caused by motor vehicle accidents, also the most common cause cited in prior studies [1-5]. The severity of the fracture displacement, location of the fracture and degree of pelvic canal narrowing are factors that must be considered in treatment selection $[6,20]$. Surgical treatment was indicated in 11 dogs $(73 \%)$, according to the criteria reported previously $[5,6,20]$. However, factors such as limited financial resources of the owner, time interval between fracture and patient evaluation, and presence of severe injuries to other organs made the surgical procedure unfeasible. As reported previously, muscle contraction and fibrosis hamper reduction of the fracture, and may cause iatrogenic surgical trauma $[5,6]$. Therefore, after 7-10 days, other methods may be more appropriate than the primary repair of the fracture [5].

Table 1 Evaluation of body mass and body size of Group 1 and 2 dogs

\begin{tabular}{lllll}
\hline & $\begin{array}{l}\text { Body mass } \\
\text { (Mean } \pm \text { SD) }\end{array}$ & $\begin{array}{l}\text { Forelimb length } \\
\text { (Mean } \pm \text { SD) }\end{array}$ & $\begin{array}{l}\text { Hind limb length } \\
\text { Mean } \pm \text { SD) }\end{array}$ & $\begin{array}{l}\text { Body length } \\
\text { (Mean } \pm \text { SD) }\end{array}$ \\
\hline Group 1 & $11.27 \pm 6.36$ & $39.79 \pm 11.63$ & $34.28 \pm 9.25$ & $44.78 \pm 9.57$ \\
Group 2 & $9.87 \pm 5.97$ & $37.71 \pm 9.96$ & $30.34 \pm 8.50$ & $41.95 \pm 1042$ \\
P-value & 0.54 & 0.60 & 0.24 & 0.45 \\
\hline
\end{tabular}

$S D$ standard deviation 
Table 2 Radiologic diagnosis of the fracture site, indication for surgery or not, time between fracture and the study, pelvic narrowing, and subjective lameness scoring for Group 2 dogs

\begin{tabular}{|c|c|c|c|c|c|c|}
\hline Case no. & Dog signalment & Fracture site & $\begin{array}{l}\text { Indication } \\
\text { for surgery }\end{array}$ & $\begin{array}{l}\text { Time of fracture } \\
\text { (months) }\end{array}$ & $\begin{array}{l}\text { Pelvic } \\
\text { narrowing }\end{array}$ & $\begin{array}{l}\text { Lameness } \\
\text { score }\end{array}$ \\
\hline 16 & $\begin{array}{l}11.3 \mathrm{~kg} \text { 2-years-old male } \\
\text { crossbreed }\end{array}$ & Right ilial body & No & 8 & No & 0 \\
\hline 17 & $\begin{array}{l}6.1 \mathrm{~kg} 2 \text {-years-old female } \\
\text { crossbreed }\end{array}$ & $\begin{array}{l}\text { Right ilial and ischial bodies, } \\
\text { and acetabulum; left ilial } \\
\text { body and ischiatic table; } \\
\text { bilateral pubic body }\end{array}$ & Yes & 4 & Yes & 2 \\
\hline 18 & $\begin{array}{l}15.5 \mathrm{~kg} 2 \text {-years-old female } \\
\text { crossbreed }\end{array}$ & $\begin{array}{l}\text { Right ilial body and ischiatic } \\
\text { tuberosity; left ischial } \\
\text { body; pubic symphysis } \\
\text { separation }\end{array}$ & Yes & 4 & Yes & 2 \\
\hline 19 & $\begin{array}{l}16.7 \mathrm{~kg} \text { 9-years-old female } \\
\text { crossbreed }\end{array}$ & $\begin{array}{l}\text { Right ilial and ischial bod- } \\
\text { ies, and acetabulum; left } \\
\text { sacroiliac separation; } \\
\text { bilateral pubic caudal } \\
\text { ramus }\end{array}$ & Yes & 87 & Yes & 2 \\
\hline 20 & $\begin{array}{l}3.5 \mathrm{~kg} 5 \text {-years-old male } \\
\text { crossbreed }\end{array}$ & $\begin{array}{l}\text { Right ischial body and } \\
\text { pubic body }\end{array}$ & No & 30 & No & 0 \\
\hline 21 & $\begin{array}{l}7.8 \mathrm{~kg} 6 \text {-years-old female } \\
\text { crossbreed }\end{array}$ & $\begin{array}{l}\text { Right acetabulum; left } \\
\text { ischial body; bilateral } \\
\text { pubic body }\end{array}$ & Yes & 16 & No & 1 \\
\hline 22 & $\begin{array}{l}5.0 \text { kg 7-years-old male } \\
\text { crossbreed }\end{array}$ & $\begin{array}{l}\text { Right pubic caudal ramus; } \\
\text { left ilial body and } \\
\text { acetabulum }\end{array}$ & Yes & 13.5 & No & 1 \\
\hline 23 & $\begin{array}{l}3.3 \mathrm{~kg} 13 \text {-years-old male } \\
\text { crossbreed }\end{array}$ & $\begin{array}{l}\text { Right pubic cranial ramus, } \\
\text { and ischial body; left } \\
\text { pubic body; pubic sym- } \\
\text { physis separation }\end{array}$ & No & 61.5 & Yes & 0 \\
\hline 24 & $\begin{array}{l}18.0 \text { kg 8-years-old female } \\
\text { crossbreed }\end{array}$ & Bilateral ilial body & Yes & 4 & Yes & 1 \\
\hline 25 & $\begin{array}{l}23.3 \mathrm{~kg} 6 \text {-years-old female } \\
\text { crossbreed }\end{array}$ & $\begin{array}{l}\text { Right ischial body, pubic } \\
\text { cranial ramus; left ischial } \\
\text { body, pubic cranial ramus } \\
\text { and acetabulum }\end{array}$ & Yes & 4 & Yes & 2 \\
\hline 26 & $\begin{array}{l}6.7 \mathrm{~kg} \text { 8-years-old female } \\
\text { crossbreed }\end{array}$ & $\begin{array}{l}\text { Left ilial and ischial bodies; } \\
\text { bilateral pubic body; } \\
\text { pubic symphysis separa- } \\
\text { tion }\end{array}$ & Yes & 8 & Yes & 0 \\
\hline 27 & $\begin{array}{l}11.5 \mathrm{~kg} 10 \text {-years-old female } \\
\text { crossbreed }\end{array}$ & Right ilial body & No & 18 & No & 2 \\
\hline 28 & $\begin{array}{l}5.8 \mathrm{~kg} 5 \text {-years-old male } \\
\text { crossbreed }\end{array}$ & $\begin{array}{l}\text { Right ilial body and } \\
\text { acetabulum; bilateral } \\
\text { pubic cranial and caudal } \\
\text { ramus; left ischial body } \\
\text { fracture; left sacroiliac } \\
\text { separation }\end{array}$ & Yes & 7 & Yes & 2 \\
\hline 29 & $\begin{array}{l}7.2 \mathrm{~kg} 3 \text {-years-old female } \\
\text { crossbreed }\end{array}$ & $\begin{array}{l}\text { Right pubic body and } \\
\text { acetabulum }\end{array}$ & Yes & 22 & No & 2 \\
\hline 30 & $\begin{array}{l}6.5 \mathrm{~kg} \text { 4-years-old male } \\
\text { dachshund }\end{array}$ & $\begin{array}{l}\text { Right ilial body, pubic body } \\
\text { and acetabulum; left } \\
\text { pubic cranial ramus }\end{array}$ & Yes & 14 & No & 1 \\
\hline
\end{tabular}

Cited complications of conservative treatment have included mal-union or pelvic canal narrowing that can result in constant or intermittent constipation, especially in cases of pelvic narrowing of $50 \%$ or more $[3,5]$. Only one dog (No. 24) showed constipation, although pelvic narrowing was present in $53 \%$ of the dogs. Although medial narrowing of the pelvis was observed, the dorsoventral displacement of a hemipelvis relative to the other allowed accommodation of the rectum. 
Table 3 Percentage of body weight (BW) distribution and symmetry indices of the kinetic data and temporospatial parameters of the hind limbs in Group 1 dogs (controls)

\begin{tabular}{|c|c|c|c|c|c|c|c|}
\hline & \multirow[t]{2}{*}{$\%$ of distribution } & \multicolumn{6}{|c|}{ Symmetry indices } \\
\hline & & Stance time (s) & Swing time (s) & $\%$ of stance & $\%$ of swing & PVF (\%BW) & VI (\%BW*s) \\
\hline Mean $\pm S D$ & $19.89 \pm 1.80$ & $5.29 \pm 4.21$ & $4.24 \pm 3.30$ & $4.77 \pm 3.29$ & $4.33 \pm 3.67$ & $6.59 \pm 4.81$ & $6.67 \pm 4.50$ \\
\hline <cutoff value & 16.28 & - & - & - & - & & \\
\hline >cutoff value & 23.50 & 13.70 & 10.84 & 11.35 & 11.68 & 16.21 & 15.67 \\
\hline
\end{tabular}

Table 4 Fracture classification, symmetry indices of the kinetic data and temporospatial parameters, and percentage of body weight (BW) distribution of the hind limbs in Group 2 dogs based on reference values obtained from Group 1 dogs

\begin{tabular}{|c|c|c|c|c|c|c|c|c|c|}
\hline \multirow[t]{2}{*}{ Case no. } & \multirow{2}{*}{$\begin{array}{l}\text { Fracture clas- } \\
\text { sification }\end{array}$} & \multicolumn{6}{|c|}{ Symmetry indices } & \multirow{2}{*}{$\begin{array}{l}\% \text { of BW } \\
\text { distribution } \\
\text { of the right } \\
\text { hind limb }\end{array}$} & \multirow{2}{*}{$\begin{array}{l}\% \text { of BW distri- } \\
\text { bution of the } \\
\text { left hind limb }\end{array}$} \\
\hline & & $\begin{array}{l}\text { Stance time } \\
\text { (s) }\end{array}$ & $\begin{array}{l}\text { Swing time } \\
\text { (s) }\end{array}$ & $\%$ of stance & $\%$ of swing & PVF (\%BW) & $\begin{array}{l}\text { VI } \\
(\% B W \times s)\end{array}$ & & \\
\hline 16 & Unilateral & 0.53 & 2.76 & 0.08 & 2.14 & 8.89 & 6.32 & 17.31 & 18.92 \\
\hline 17 & Bilateral & 9.16 & 4.17 & 3.17 & 1.83 & 11.15 & 3.19 & 18.01 & 20.14 \\
\hline 18 & Bilateral & 13.33 & 4.14 & 10.78 & 6.70 & 12.73 & 23.40 & 16.02 & 18.20 \\
\hline 19 & Bilateral & 26.49 & 22.82 & 24.89 & 24.42 & 20.61 & 46.60 & 14.88 & 18.29 \\
\hline 20 & Unilateral & 14.00 & 3.80 & 11.52 & 6.29 & 6.22 & 2.88 & 17.25 & 18.36 \\
\hline 21 & Bilateral & 5.24 & 7.19 & 10.49 & 1.93 & 10.98 & 3.96 & 21.00 & 18.82 \\
\hline 22 & Bilateral & 10.53 & 7.41 & 12.44 & 5.49 & 9.36 & 3.54 & 22.54 & 24.75 \\
\hline 23 & Bilateral & 5.71 & 2.88 & 6.76 & 1.83 & 25.88 & 30.14 & 23.92 & 18.44 \\
\hline 24 & Bilateral & 10.06 & 9.38 & 9.40 & 10.03 & 19.22 & 23.33 & 18.96 & 22.99 \\
\hline 25 & Bilateral & 7.09 & 8.58 & 6.25 & 9.42 & 32.37 & 30.72 & 20.81 & 15.01 \\
\hline 26 & Bilateral & 0.67 & 1.75 & 0.49 & 2.92 & 4.32 & 4.98 & 25.60 & 26.73 \\
\hline 27 & Unilateral & 0.00 & 3.15 & 2.26 & 0.89 & 8.10 & 7.10 & 20.46 & 18.86 \\
\hline 28 & Bilateral & 11.57 & 9.00 & 11.94 & 8.63 & 21.53 & 24.49 & 21.33 & 17.18 \\
\hline 29 & Unilateral & 32.68 & 15.25 & 23.49 & 24.53 & 26.05 & 42.86 & 14.72 & 19.12 \\
\hline 30 & Bilateral & 4.20 & 7.53 & 5.43 & 2.09 & 12.04 & 15.19 & 19.73 & 17.49 \\
\hline
\end{tabular}

Values exceeding the cutoff values are shown in italics

In addition, malalignment and/or fracture instability may cause limited movement of the hip joint [6], as observed unilaterally in one dog (No. 26) due to severe hemipelvic dislocation. On the other hand, malalignment can induce pain, which was induced in $27 \%$ of dogs on forced extension of the hip joint. In addition, signs of bone healing was found by radiographic examination in $30 \%$ of the cases. Movement of the fracture was not detectable by physical examination in the other cases, probably due to fibrosis around the fracture. Usually contraction of the pelvic muscles stabilizes the fractures not internally displaced [21].

Although the morphometric measurements (lengths of the limbs and body length) did not differ statistically between the groups, as the population heterogeneity required that the evaluations of kinetic data and temporal-spatial parameters between groups were done using SI, as suggested in other studies [9]. The soundness of
Group 1 dogs was confirmed by absence of significant differences in kinetic data and temporospatial parameters between forelimbs or between hind limbs. In addition, the percentage of BW distribution was approximately $30 \%$ on each forelimb and $20 \%$ on each hind limb, consistent with a previous description of clinically healthy dogs in locomotion over a pressure-sensing walkway [22].

With respect to Group 2, the four dogs that showed a lower percentage of BW distribution in one of the hind limbs had a lameness score of 2 . Three of these dogs (Nos. 18,19 , and 25) had bilateral fractures with more severe radiographic changes on the side where less weight was distributed, while dog No. 29 had pelvis unilateral fracture with acetabular involvement. In a study that induced lameness in the right hind limb, it was observed that the dogs walking and trotting on an instrumented treadmill had all parameters decreased in this limb, and the center of mass was shifted to the contralateral side and 
cranio-caudally to the side opposite to the right hind limb [10].

Two dogs in the present study showed higher percentage of BW distribution in one of the hind limbs (Nos. 22, 23), and presented respective lameness scores of 1 and 0. Both had bilateral fractures, but more severe on one side; one with acetabular involvement (No. 22) and the other with fracture of the body of the ischium (No. 23), which justifies $\mathrm{BW}$ redistribution to the less affected side. On the other hand, dog No. 26, whose lameness score was 0 , showed higher BW redistribution to both hind limbs, suggesting alterations in forelimbs. Thus, the lameness score determined in the present study did not always correspond with kinetic data. Similarly, in a study of dogs undergoing unilateral tibial osteotomy treated with external fixator, it was observed that subjective lameness scoring scales did not reproduce the data obtained by force platform analysis [23].

Five dogs showed changes in SI of the temporospatial parameters (Nos. 19, 20, 22, 28, and 29). In relation to pelvic fractures, three dogs had bilateral fractures (Nos. 19, 22, and 28) and two unilateral (Nos. 20 and 29). However, SI must be evaluated together with the other data, since low values of the temporospatial variables may suggest asymmetry, which may not be a true representation [24]. For example, SI of the temporospatial parameters of the dogs Nos. 20 and 22 showed asymmetry in percentage of stance time, but not in percentage of swing time, suggesting capture artefact. In addition, SI of the PVF and VI must also be evaluated together with the percentage of body weight distribution, especially in bilateral fractures. For example, the dog No. 26 had PVF and VI without SI alteration, but the percentage of BW distribution was higher in both hind limbs. Thus, only the dog Nos. 19 and 29 showed true changes in SI of the temporospatial parameters. These parameters are suggestive of inadequate function of the limbs, since the ratio of duration between the time when the foot is on the ground (stance time) and the time when the foot is off the ground (swing time) $[13,25,26]$ was not maintained. In addition, both dogs showed changes in kinetic data.

Although $75 \%$ of dogs with pelvic fractures are able to recover without a surgical procedure [4], analyzing the data obtained in the present study, $46.7 \%$ of the dogs had some abnormality of percentage of BW distribution, suggesting that the conservative treatment may not be adequate if a normal biomechanical performance is desired after treatment.

A limitation that needs to be considered when interpreting the findings of the present study is the small sample size based on fracture type. Another limitation relates to a retrospective nature of the study as treatment was not determined exclusively by the fracture type.

\section{Conclusions}

Dogs with pelvic fractures treated conservatively may present changes in percentage of BW distribution and SI of the kinetic and temporospatial parameters. The conservative treatment can cause persistent abnormal gait.

\section{Abbreviations}

BW: body weight; LH: left hind limb; PVF: peak vertical force; RL: right hind limb; SD: standard deviation; SI: symmetry index; VI: vertical impulse.

\section{Authors' contributions}

FGV performed acquisition, analysis and interpretation of data. SCR and FSA contributed on conception and design of the study, analysis and interpretation of data. FSA and AM performed statistical analysis. MJM and DPD performed radiographic analysis. WTK and LRM helped on collecting data. All authors read and approved the final manuscript.

\section{Author details}

${ }^{1}$ Department of Veterinary Surgery and Anesthesiology, School of Veterinary Medicine and Animal Science, Botucatu, SP, Brazil. ${ }^{2}$ Department of Animal Reproduction and Veterinary Radiology, School of Veterinary Medicine and Animal Science, Botucatu, SP, Brazil. ${ }^{3}$ Department of Clinic Veterinary, School of Veterinary Medicine and Animal Science, Botucatu, SP, Brazil.

\section{Acknowledgements}

This work was supported by FAPESP (The State of São Paulo Research Foundation) under Grant 2013/16689-8.

\section{Compliance with ethical guidelines}

\section{Competing interests}

The authors declare that they have no competing interests.

Received: 4 February 2015 Accepted: 24 September 2015

Published online: 05 October 2015

\section{References}

1. Newton CD. Fractures of the pelvis. In: Newton CD, Nunamaker DM, editors. Textbook of small animal orthopaedics. Philadelphia: JB Lippincott Company; 1985. p. 1-11.

2. Schwarz PD. Fracture biomechanics of the appendicular skeleton: causes and assessment. In: Bojrab MJ, Smeak DD, Bloomberg MS, editors. Disease mechanisms in small animal surgery. Philadelphia: Lea \& Febiger; 1993. p. 1009-26.

3. Piermattei DL, Flo GL, DeCamp CE. Fractures of the pelvis. In: Piermattei DL, Flo GL, DeCamp CE, editors. Handbook of small animal orthopedics and fracture repair. Philadelphia: Saunders; 2006. p. 433-460.

4. Harasen G. Pelvic fractures. Can Vet J. 2007:48:427-8.

5. DeCamp CE. Fractures of the pelvis. In: Tobias KM, Johnston SA, editors. Veterinary surgery small animal. Canada: Elsevier Saunders; 2012. p. $801-815$.

6. Denny HR, Butterworth SJ. The pelvis. In: Denny HR, Butterworth SJ, editors. A guide to canine and feline orthopaedic surgery. Oxford: Blackwell Science; 2000. p. 441-54.

7. Gillette RL, Angle TC. Recent development in canine locomotor analysis. A review. Vet J. 2008;178:165-76.

8. Gordon-Evans WJ. Gait analysis. In: Tobias KM, Johnston SA, editors. Veterinary surgery small animal. Canada: Elsevier Saunders; 2012. p. 1190-1196.

9. Fanchon L, Grandjean D. Accuracy of asymmetry indices of ground reaction forces for diagnosis of hind limb lameness in dogs. Am J Vet Res. 2007;68:1089-94.

10. Fischer S, Anders A, Nolte I, Schilling N. Compensatory load redistribution in walking and trotting dogs with hindlimb lameness. Vet J. 2013;197:746-52. 
11. Horstman CL, Conzemius MG, Evans R, Gordon WJ. Assessing the efficacy of perioperative oral carprofen after cranial cruciate surgery using noinvasive, objective pressure platform gait analysis. Vet Surg. 2004;33:286-92.

12. LeQuang T, Maitre $P$, Roger T, Viguier $E$. Is a pressure walkway system able to highlight a lameness in dog? J Anim Vet Adv. 2009;8:1936-44.

13. Gordon-Evans WJ, Evans RB, Conzemius MG. Accuracy of spatiotemporal variables in gait analysis of neurologic dogs. J Neurotrauma. 2009;26:1055-60.

14. Souza ANA, Tatarunas AC, Matera JM. Evaluation of vertical forces in the pads of Pitbulls with cranial cruciate ligament rupture. BMC Vet Res. 2014;10:1-6.

15. Besancon MF, Conzemius MG, Derrick TR, Ritter MJ. Comparison of vertical forces in normal greyhounds between force platform and pressure walkway measurement systems. Vet Comp Orthop Traumatol. 2003;16:153-7.

16. Lascelles BD, Roe SC, Smith E, Reynolds L, Markham J, Marcellin-Little D, Bergh MS, Budsberg SC. Evaluation of a pressure walkway system for measurement of vertical limb forces in clinically normal dogs. Am J Vet Res. 2006;67:227-82.

17. Gordon-Evans WJ. Gait analysis. In: Tobias KM, Johnston SA, editors. Veterinary surgery small animal. Canada: Elsevier Saunders; 2012. p. 1190-1196.

18. Millis DL, Levine D. Canine rehabilitation and physical therapy. Philadelphia: Elsevier Saunders; 2014.
19. Voss K, Imhof J, Kaestner S, Montavon PM. Force plate gait analysis at the walk and trot in dogs with low-grade hindlimb lameness. Vet Comp Orthop Traumatol. 2007;20:299-304.

20. Olmstead ML. Fractures of the bones of the hind limb. In: Olmstead ML, editor. Small animal orthopedics. St. Louis: Mosby; 1995. p. 219-43.

21. Dunbar AD. Evaluating pelvic fractures: indications for surgical correction. Vet Med Small Anim Clin. 1984;79:1047-52.

22. Kim J, Kazmierczak KA, Breur GJ. Comparison of temporospatial and kinetic variables of walking in small and large dogs on a pressure-sensing walkway. Am J Vet Res. 2011;72:1171-7.

23. Quinn MM, Keuler NS, Lu Y, Faria MLE, Muir P, Markel MD. Evaluation of agreement between numerical rating scales, visual analogue scoring scales, and force plate gait analysis in dogs. Vet Surg. 2007;36:360-7.

24. Budsberg SC, Jevens DJ, Brown J, Foutz TL, DeCamp CE, Reece L. Evaluation of limb symmetry indices, using ground reaction forces in healthy dogs. Am J Vet Res. 1993;54:1569-74

25. Light VA, Steiss JE, Montgomery RD, Rumph PF, Wright JC. Temporal-spatial gait analysis by use of a portable walkway system in healthy Labrador Retrievers at a walk. Am J Vet Res. 2010;71:997-1002.

26. Agostinho FS, Rahal SC, Araujo FAP, Conceição RT, Hussni CA, El-Warrak $A O$, Monteiro FOB. Gait analysis in clinically healthy sheep from three different age groups using a pressure-sensitive walkway. BMC Vet Res. 2012;8:1-7.

\section{Submit your next manuscript to BioMed Central and take full advantage of:}

- Convenient online submission

- Thorough peer review

- No space constraints or color figure charges

- Immediate publication on acceptance

- Inclusion in PubMed, CAS, Scopus and Google Scholar

- Research which is freely available for redistribution

Submit your manuscript at

www.biomedcentral.com/submit

(O) Biomed Central 